\title{
EFFECT OF WATER QUALITY AND LATERALS FLUSHING FREQUENCY ON EMITTERS PERFORMANCE
}

\author{
M. A. Kassem* and M. S. Omran*
}

ABSTRACT

The effect of two different water qualities (groundwater $(\boldsymbol{G W})$ and treated sewage effluent (TSE)) and four laterals flushing frequency treatments (non flushing (NF), monthly flushing (MF), fortnightly flushing (FF) and a weekly flushing (WF)) on emitters performance, were studied for total operational time, $1440 \mathrm{~h}$. The emitters performance were evaluated, using the reduction of emitter discharge $\left(\mathbf{q}_{\mathbf{r}}\right)$, the relative emitter discharge $(\mathbf{R})$, the coefficient of variation of emitter discharge $(\mathbf{C V})$, the distribution uniformity (DU) and Christiansen uniformity coefficient (CU). Results indicated that all indices were affected by water quality, laterals flushing frequency and operational time. The values of $\mathbf{q}_{\mathbf{r}}$ and $\mathbf{C V}$ for the TSE treatments were greater than those for the $\boldsymbol{G W}$ treatments. The values of $\mathbf{R}, \mathbf{D U}$ and $\mathbf{C U}$ for the $\mathbf{T S E}$ treatments were lower than those for the $\mathbf{G W}$ treatments. The $\mathrm{q}_{\mathrm{r}}$ and $\mathbf{C V}$ increased and the $\boldsymbol{R}, \mathbf{D U}$ and $\mathbf{C U}$ decreased as operational time increasing for the $\boldsymbol{G W}$ and $\mathbf{T S E}$ treatments. For both $\mathbf{G W}$ and $\boldsymbol{T S E}$ treatments, the $\mathbf{q}_{\mathrm{r}}$ and the $\mathbf{C V}$ were greater, and the $\boldsymbol{R}, \mathbf{D U}$ and $\mathbf{C U}$ were smaller of $\mathbf{W F}$ treatment than those for another treatments. Laterals flushing frequency efficiently alleviate emitter clogging and improved the emitters performance. In a conclusion, WF treatment showed a suitable emitters performance than another treatments of laterals flushing.

\section{INTRODUCTION}

7 he use of treated sewage effluents (TSE) in agriculture is a viable alternative in areas where water is scarce or when there is intense competition for its use. Treated sewage effluent (TSE) has been used for many years in world for agriculture (Zeng and Zhu, 2004) and for landscaping (Guo et al., 2006) and (Yang et al., 2003).

* Assoc. Prof., Ag. Eng. Dept., Fac. of Ag., Cairo Univ. 
The best way to apply $\boldsymbol{T S E}$ from the public health and environmental points of view is by means of drip irrigation (Peng et al., 2006). Drip irrigation system must has good and consistent filtration, water treatment, flushing and maintenance plans to ensure long economic life (Lamm and Camp, 2007). Filtration systems do not normally remove clay and silt particles, algae and bacteria because they are too small for typical economical filtration. These particles may travel through the filters as individual particles, then flocculate or become attached to organic residues and eventually become large enough to clog emitters (Nakayama et al., 2007). Therefore, laterals flushing is periodically needed to remove these particles and organisms that are accumulated within the laterals (Ayars et al., 2007) and (Zhang et al., 2007).

The drip irrigation system should be designed, so that it can be flushed properly. To be effective, flushing must be done often enough and at an appropriate velocity to dislodge and transport the accumulated sediments (Nakayama et al., 2007). A minimum flushing velocity of $0.3 \mathrm{~m} / \mathrm{s}$ is recommended for microirrigation systems (ASAE, 2003). However, a flushing velocity of $0.5-0.6 \mathrm{~m} / \mathrm{s}$ may be needed when larger particle sizes need to be removed, like when coarser filters are used (Hills and Brenes, 2001 and Nakayama et al., 2007). There is not a general agreement on what is the best flushing frequency. Several researchers have studied different flushing frequencies: daily and every two weeks with stored effluents (Ravina et al., 1997), twice per week and once per week with a secondary clarified effluent (Tajrishy et al., 1994 ,Hills et al., 2000) and (Hills and Brenes, 2001) or fortnightly and monthly with stored $\boldsymbol{G W}$ (Hills et al., 2000). However, in many areas, only one flushing is carried out at the beginning and/or at the ending of irrigation season.

$\boldsymbol{T S E}$ is turbid and rich in ions, organic materials and microorganisms (Ma et al., 2006). Consequently, the emitter is prone to partial or complete clogging with TSE (Capra and Scicolone, 2007). The causes of clogging differ based on emitter dimension and positions in lateral (Ahmed et al., 2007). De Kreij et al. (2003) found that the tube emitter system with laminar flow suffers more severe clogging than the labyrinth system with turbulent flow. Capra and Scicolone (2004) found that vortex emitters 
are more sensitive to clogging than labyrinth emitters. Ravina et al. (1997) found that fast flow can limit the biological growth on the pipe wall and thus lower the risk of clogging; more clogged emitters are found at the tailing part than at the leading part of the drip lateral. Emitter clogging greatly reduces the relative emitter discharge and water distribution uniformity in irrigated fields (Puig-Bargues et al., 2005). To prevent emitter clogging, some methods have been used on both experimental and on field scales. Filtering and flushing drip lines are simple and useful methods to prevent emitter clogging, particularly for physical clogging (Nakayama and Bucks, 1991). Filtering can prevent inorganic particles and organic materials suspended in water from entering the drip-irrigation system. Flushing drip lines can clear the inorganic and organic materials precipitated in emitter orifices and on the inside-wall of drip hoses out of the system. Emitters performance and clogging degree varies based on water quality and laterals flushing frequency.

Therefore, the objectives of this work are: (1) to study the effect of water quality and laterals flushing frequency in emitters performance and (2) to recommend a suitable laterals flushing frequency for both $\boldsymbol{T S E}$ and $\boldsymbol{G W}$.

\section{MATERIALS AND METHODS}

\section{Layout of Experimental field}

Field experiments were conducted at Agricultural and Veterinary Research Station, Faculty of Agriculture and Veterinary Medicine, AlQassim University, from February 2010 to May 2010. In the present work, two types of water quality and four treatments of laterals flushing frequency were used to test their effects on emitters performance. The water qualities were groundwater $(\boldsymbol{G W})$ and treated sewage effluent $(\boldsymbol{T S E})$. The four treatments of laterals flushing frequency were carried out for different types of water qualities: non flushing (NF), monthly flushing frequency (MF), fortnightly flushing frequency (FF), and a weekly flushing frequency (WF). The $\boldsymbol{G W}$ originating from a local well, $500 \mathrm{~m}$ deep and the $\boldsymbol{T S E}$ was supplied from a line was connected with Qassim Waste Water Treatment Plant. One type of emitters most commonly used 
in Qassim area of Saudi Arabia was selected for the experiment. This type is inline-labyrinth emitter, with a turbulent flow.

The experimental field was divided in to two main plots, the first plot for $\boldsymbol{G W}$ and the second for $\boldsymbol{T S E}$. Each main plot had four sub-plots of laterals flushing frequencies. A randomized complete block was used with three replications of laterals flushing frequency treatments. At the head of each plot, a water reservoir was used to store irrigation water, its volume capacity was $24 \mathrm{~m}^{3}$ ( $4 \mathrm{~m}$ length, $3 \mathrm{~m}$ width and $2 \mathrm{~m}$ depth). At the inlet of it, a PVC pipe of 4 inch outside diameter was fixed. The water reservoir was filled with irrigation water every day at $6 \mathrm{am}$. The irrigation water was pumped from each reservoir using a pump (discharge of $0.8 \mathrm{~m}^{3} / \mathrm{h}$, and pressure head of $150 \mathrm{kPa}$ ), followed by a sand filter (the sand was supplied had an effective size of $0.32 \mathrm{~mm}$ and uniformity coefficient $3.17)$ and a screen filter ( 80 mesh or $180 \mu \mathrm{m})$ in succession. Also, a flow meter was installed, followed by a pressure regulating valve and a pressure meter. The pressure regulating valve was used to maintain a pressure of $100 \mathrm{kPa}$ in the middle of the lateral, as measured with a pressure meter. After the filtration system, 24 laterals $30 \mathrm{~m}$ long were installed on a 0.175 ha field ( $50 \mathrm{~m}$ long and $35 \mathrm{~m}$ wide) with an average slope of $0.15 \%$ in the wide direction. Sand filter filled with $175 \mathrm{~kg}$ of sand as a single filtration layer. A ball valve was installed at the inlet to each lateral for onsite flow control and at every lateral end for flushing. Flushing was carried out for $5 \mathrm{~min}$ at a velocity of $0.60 \mathrm{~m} / \mathrm{s}$. To avoid interference with the primary focus of the study, the evaluation of flushing frequency, no chemical treatments of the irrigation water were conducted to prevent emitter clogging.

The discharge of each emitter was measured every 15 days by using the containers. During the field experiments, the trickle-irrigation system was running $12 \mathrm{~h}$ daily. Therefore, the total operational time was $1440 \mathrm{~h}$ from February $1^{\text {st }}, 2010$ to May $30^{\text {th }}, 2010$.

\section{Experimental measurements}

The characteristics of tertiary $\boldsymbol{T S E}$ were measured monthly, on days of $15^{\text {th }}$ Feb, $16^{\text {th }}$ Mar, 15 ${ }^{\text {th }}$ April and $14^{\text {th }}$ May. While, the characteristics of $\boldsymbol{G W}$ were measured only on day $5^{\text {th }}$ Mar, because $\boldsymbol{G W}$ properties varied 
little on a yearly scale (Hills and Brenes, 2001). The mean values of some characteristics of $\boldsymbol{G W}$ and $\boldsymbol{T S E}$ are shown in table (1). The discharges of emitters with the application of $\boldsymbol{G W}$ and $\boldsymbol{T S E}$ were measured every 15 days. Before each measurement, the 5-L containers were put precisely beneath the emitters. After $1 \mathrm{~h}$ operation of the system, the water volume of each container with emitted water was measured using a graduate jar. The emitter discharge was recorded in volume per unit time, $1 / \mathrm{h}$.

Table (1): Physical and chemical properties of the tertiary treated sewage effluent (TSE) and groundwater $(\boldsymbol{G W})$

\begin{tabular}{|l|c|c|c|c|c|c|c|c|c|c|c|}
\hline \hline Terms & $\mathrm{pH}$ & $\begin{array}{c}\mathrm{EC}, \\
\mathrm{mm} / \mathrm{cm}\end{array}$ & $\begin{array}{c}\mathrm{TDS}, \\
\mathrm{mg}\end{array}$ & $\mathrm{COD}$ & $\mathrm{BOD}$ & $\mathrm{Ca}^{-}$ & $\mathrm{Mg}$ & $\mathrm{Na}^{-}$ & $\mathrm{K}^{-}$ & $\mathrm{Fe}$ & $\mathrm{NH}_{4}$ \\
\hline $\boldsymbol{T S} \boldsymbol{E}$ & 7.7 & 2.3 & 795.8 & 251 & 87.2 & 539 & 212 & 441 & 80 & 4 & $64.5^{-}$ \\
\hline $\boldsymbol{G W}$ & 7.4 & 1.24 & 18.2 & $\mathrm{ND}$ & $\mathrm{ND}$ & 3 & 1.4 & 29 & 0.4 & $\mathrm{ND}$ & 3.1 \\
\hline
\end{tabular}

TDS: Total dissolved solids, COD: chemical oxygen demand, BOD: biochemical oxygen demand, ND: means the content of the corresponding items is too small to be detected.

Before the field experiments, emitter discharge was determined in a laboratory by using 100 new emitters at an operational pressure of 100 $\mathrm{kPa}$ with $\boldsymbol{G} \boldsymbol{W}$. The emitter discharge exponent, flow-path dimension and the manufacturing coefficient of variation $(\mathrm{CVm})$ for the inline-labyrinth emitter are listed in table (2), which were from the corresponding emitter manufacturers. According to the ASAE standard EP405.1 (ASAE Standards, 2003) on manufacturing coefficient of variation for emitters, emitter can be classified as excellent emitter types $(\mathrm{CVm}<0.05)$. The working pressures at inlet, middle and ending of each lateral were measured by digital manometer $(0.07 \%$ accuracy) that was placed in a pressure reading socket. The values of pressure uniformity were determined and found to be greater than $96 \%$ for all treatments, meaning that pressure distribution along the lateral was very uniform. Since the emitter manufacturing coefficient of variation was low, the reductions of emitter discharges can primarily be explained by emitter clogging (PuigBargues et al., 2005). 
Table (2): Hydraulic characteristics and flow-path dimension of the tested emitter

\begin{tabular}{|l|c|}
\hline Emitter characteristics & Value \\
\hline Discharge, 1/h & 2.83 \\
\hline Manufacturing coefficient of variation (CV) & 0.016 \\
\hline Discharge exponent & 0.480 \\
\hline Minimum flow-path, mm & 1.53 \\
\hline Distance between emitters, cm & 40 \\
\hline
\end{tabular}

\section{Assessment of emitter performance}

The criteria used for assessing the emitters performance were the mean emitter discharge of each lateral $\left(\mathbf{q}^{-}\right)$, the reduction of emitter discharge $\left(\mathbf{q}_{\mathbf{r}}\right)$, the relative emitter discharge $(\mathbf{R})$, the coefficient of variation $(\mathbf{C V})$ of the emitter discharge in a lateral, the distribution uniformity (DU) and Christiansen uniformity coefficient (CU).

The reduction of the mean emitter discharge in percentage $\left(\mathbf{q}_{\mathbf{r}}\right)$ and the relative emitter discharge ( $\mathbf{R})$ were calculated as (Keller and Karmeli, 1974):

$$
\begin{gathered}
q_{r}=100 \times\left(1-\frac{q^{-}}{q_{i n}}\right) \\
R=\frac{q^{-}}{q_{\text {in }}}
\end{gathered}
$$

Where:

$\mathrm{q}^{-}$is the mean emitter discharges of each lateral, $1 / \mathrm{h}$;

$\mathrm{q}_{\text {in }}$ is the mean discharge of 100 new emitters at the same operation pressure, $1 / \mathrm{h}$.

The coefficient of variation (CV) of the emitter discharge in a lateral was calculated as (Bralts and Kesner, 1983), the distribution uniformity (DU) and Cristiansen uniformity coefficient $(\mathbf{C U})$ were calculated as (Keller and Karmeli, 1974):

$$
C V=100 \times \frac{S D}{q^{-}}
$$




$$
\begin{gathered}
D U=100 \times\left(\frac{q_{\min 1 / 4}}{q^{-}}\right) \\
C U=100 \times\left(1-\sum_{i=1}^{n} \frac{\left|q_{i}-q^{-}\right|}{n \times q^{-}}\right)
\end{gathered}
$$

Where:

SD is the standard deviation of emitter discharge;

$\mathrm{q}_{\min 1 / 4}$ is the mean discharge of lower quarter, $1 / \mathrm{h}$;

$\mathrm{q}_{\mathrm{i}}$ is the measured discharge of emitter $\mathrm{i}, \mathrm{l} / \mathrm{h}$;

$\mathrm{n}$ is the total number of emitters in each lateral.

The two indices DU and $\mathbf{C U}$ assume different meanings. The former shows the condition of the smallest emitter discharge as compared with that of the average discharge, whereas the latter represents the deviation of discharge from its mean value.

\section{Statistical analyses}

Statistical analyses were carried out by using the SPSS 11.5 software for Windows (SPSS Inc., Chicago, IL, USA). The differences of emitter performance indices among two water qualities and four laterals flushing were analyzed at a significant level of 0.05 or less.

\section{RESULTS AND DISCUSSION}

\section{1-Mean emitter discharges $(\bar{q})$ and emitter discharge reduction $\left(q_{r}\right)$ for each lateral during the experiment}

The results of statistical analysis, for the effect of water quality and laterals flushing frequency and interactions on emitter performance are shown in table (3). The results showed highly significant effect of these factors on $\mathbf{q}$ and $\mathbf{q}_{\mathbf{r}}$. The mean emitter discharges for each lateral ( $\mathbf{q}$ ) for four laterals flushing frequency treatments for the application of both GW and TSE during the experiment are shown in table (4). The values of q varies with water quality, laterals flushing frequency and operational time. The value of $\mathbf{q}$ for $\mathbf{N F}$ treatment decreased greatly with the operational time in comparison with that of WF and FF treatments. The value of $\mathbf{q}$ is greatly influenced by TSE in comparison with $\mathbf{G W}$. The 
values of $\mathbf{q}$ for NF treatment decreased greatly with the operational time in comparison with that of FF and WF treatments.

Table (3): Analysis of variance (ANOVA) for the effect of water quality and laterals flushing frequency on emitter performance

\begin{tabular}{|l|c|c|c|c|c|c|c||}
\hline \multirow{2}{*}{$\begin{array}{c}\text { Source of } \\
\text { variation }\end{array}$} & \multirow{2}{*}{$\mathbf{d f}$} & \multicolumn{2}{|c|}{$\mathbf{q}^{-}$} & \multicolumn{2}{c|}{$\mathbf{q}$} & \multicolumn{2}{c|}{$\mathbf{R}$} \\
\cline { 3 - 9 } & & $\mathbf{M S}$ & Sign & MS & Sign. & MS & Sign. \\
\hline Replication & 2 & 0.091 & $* *$ & 2.734 & $* *$ & 0.004 & $* *$ \\
\hline $\begin{array}{l}\text { Water quality } \\
\text { (A) }\end{array}$ & 1 & 2.795 & $* *$ & 3670.344 & $* *$ & 0.366 & $* *$ \\
\hline $\begin{array}{l}\text { Flushing } \\
\text { frequency (B) }\end{array}$ & 3 & 1.615 & $* *$ & 2025.329 & $* *$ & 0.205 & $* *$ \\
\hline AB & 3 & 0.487 & $* *$ & 638.305 & $* *$ & 0.062 & $* *$ \\
\hline Time (C) & 8 & 0.577 & $* *$ & 754.985 & $* *$ & 0.075 & $* *$ \\
\hline AC & 8 & 0.192 & $* *$ & 243.376 & $* *$ & 0.024 & $* *$ \\
\hline BC & 24 & 0.127 & $* *$ & 151.293 & $* *$ & 0.016 & $* *$ \\
\hline ABC & 24 & 0.035 & $* *$ & 46.401 & $* *$ & 0.005 & $* *$ \\
\hline Error & 142 & 0.002 & & 0.21 & & 0.000 & \\
\hline
\end{tabular}

** high significant, $\mathrm{q}^{-}$is the mean emitter discharges of each lateral, $\mathrm{q}_{\mathrm{r}}$ is the emitter discharge reduction, $\mathrm{R}$ is relative emitter discharge

Table (4): Effect of water quality and laterals flushing frequency on mean emitter discharge of each lateral $\left(\mathbf{q}^{-}\right)$

\begin{tabular}{|c|c|c|c|c|c|c|c|c|}
\hline \multirow{3}{*}{ = } & \multicolumn{8}{|c|}{ Treatments } \\
\hline & \multicolumn{4}{|c|}{ Groundwater $(G W)$} & \multicolumn{4}{|c|}{ Treated sewage effluent (TSE) } \\
\hline & NF & MF & FF & WF & NF & MF & FF & WF \\
\hline $\mathbf{0}$ & 2.83 & 2.83 & 2.83 & 2.83 & 2.83 & 2.83 & 2.83 & 2.83 \\
\hline 180 & 2.82 & 2.8 & 2.82 & 2.81 & 2.82 & 2.82 & 2.82 & 2.81 \\
\hline 360 & 2.78 & 2.8 & 2.8 & 2.8 & 2.7 & 2.7 & 2.7 & 2.73 \\
\hline 540 & 2.7 & 2.75 & 2.79 & 2.81 & 2.3 & 2.66 & 2.75 & 2.75 \\
\hline 720 & 2.63 & 2.7 & 2.78 & 2.82 & 1.95 & 2.4 & 2.75 & 2.72 \\
\hline 900 & 2.55 & 2.6 & 2.79 & 2.8 & 1.8 & 2.25 & 2.7 & 2.71 \\
\hline 1080 & 2.52 & 2.58 & 2.78 & 2.82 & 1.7 & 2.17 & 2.69 & 2.65 \\
\hline 1260 & 2.5 & 2.55 & 2.77 & 2.8 & 1.62 & 2.1 & 2.6 & 2.61 \\
\hline 1440 & 2.5 & 2.55 & 2.77 & 2.8 & 1.6 & 2 & 2.55 & 2.6 \\
\hline
\end{tabular}

LSD for $\boldsymbol{G W}$ and $\boldsymbol{T S E}$ treatments $=0.22, \mathbf{N F}$ : non flushing, MF: monthly flushing, FF: fortnightly flushing and WF: weekly flushing 
For WF treatment, there are no significant differences $(\mathrm{P}>0.05)$ for the values of $\mathbf{q}$ between the $\boldsymbol{G} \boldsymbol{W}$ treatment and the $\boldsymbol{T S E}$ treatment. For $\mathbf{F F}$ treatment, the difference in the values of $\mathbf{q}$ between the $\boldsymbol{G W}$ treatment and the TSE treatment is not significant $(\mathrm{P}>0.05)$ before $1260 \mathrm{~h}$ of operational time, while after that time the values of $\mathbf{q}$ for the $\boldsymbol{T S E}$ treatment decreases greatly, it is about $8.9 \%$ lower than the discharge for the $\boldsymbol{G W}$ treatment. The small particles of $\boldsymbol{T S E}$ may travel through the filters as individual particles, then flocculate or become attached to organic residues and eventually become large enough to clog emitters (Nakayama et al., 2007).

For MF treatment, the difference in emitter discharge between the $\boldsymbol{G W}$ treatment and the $\boldsymbol{T S E}$ treatment is not significant $(\mathrm{P}>0.05)$ before $720 \mathrm{~h}$ of operational time, while after that time the emitter discharge for the $\boldsymbol{T S E}$ treatment decreases greatly due to severe clogging and is about $13.46 \%$ lower than the discharge for the $\boldsymbol{G} \boldsymbol{W}$ treatment.

For NF treatment, the difference in emitter discharge between the $\boldsymbol{G W}$ treatment and the $\boldsymbol{T S E}$ treatment is not significant $(\mathrm{P}>0.05)$ before $540 \mathrm{~h}$ of operational time, while after that time the emitter discharge for the $\boldsymbol{T S E}$ treatment decreases greatly due to severe clogging and is about $25.85 \%$ lower than the discharge for the $\boldsymbol{G W}$ treatment.

The reduction of mean emitter discharges $\left(\mathbf{q}_{\mathbf{r}}\right)$ for four laterals flushing frequency treatments for the application of both $\boldsymbol{G W}$ and $\boldsymbol{T S E}$ during the experiment are shown in Fig. (1). At the end of the experiment, the maximum value of $\mathbf{q}_{\mathbf{r}}$ was $43.3 \%$ for treatment of NF using $\boldsymbol{T S E}$. While the minimum values of $\mathbf{q}_{\mathbf{r}}$ were $1.06 \%$ and $8.12 \%$ for treatments WF with $\boldsymbol{G W}$ and WF with $\boldsymbol{T S E}$, respectively. Discharge reductions can primarily be explained by emitter clogging. (Ravina et al., 1997; Liu and Huang, 2009). Figure 1 (c and d) shows that the percentage of $\mathbf{q}_{\mathbf{r}}$ values for treatments of $\mathbf{W F}$ and $\mathbf{F F}$ are linearly related to the operational time, with determination coefficients of $\mathrm{R}^{2}=0.86$ and 0.83 for both the $\boldsymbol{G W}$ and the $\boldsymbol{T S E}$ treatments, respectively. Decreasing the values of $\mathbf{q}_{\mathbf{r}}$, the percentages of emitter clogging were increased. (Liu and Huang, 2009). 


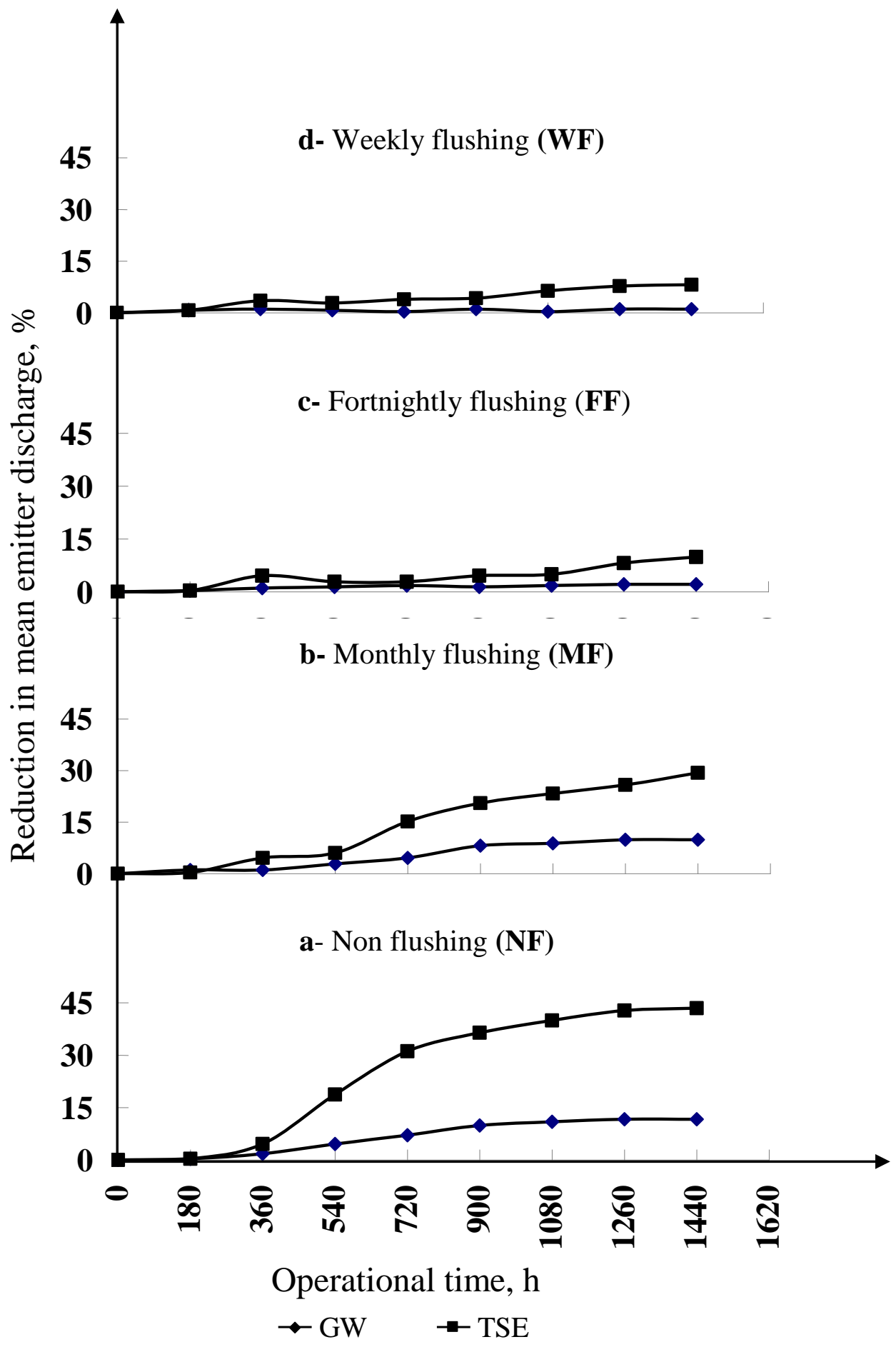

Fig. (1): Effect of water quality and laterals flushing frequency on the reduction in mean emitter discharges $\left(\mathbf{q}_{\mathbf{r}}\right)$ during the experiment 


\section{Relative emitter discharge ( $R$ ) during the experiment}

The results of statistical analysis for the effect of water quality and laterals flushing frequency and interactions on $\mathbf{R}$ values during the experiment, table (3), showed highly significant effect of these factors on $\mathbf{R}$ values.

The values of relative emitter discharge $(\mathbf{R})$ for the tested emitter of four laterals flushing frequency treatments for the application of both $\boldsymbol{G W}$ and $\boldsymbol{T S E}$ during the experiment are shown in Fig. (2). From Fig. (2) it is clear that the $\mathbf{R}$ values for all treatments based on laterals flushing frequency, water quality and operational time. The partially and completely clogged emitters were analyzed using the relative emitter discharge (R). Capra and Scicolone (2007) divided the relative emitter discharge into three classes; high relative emitter discharge class $(\mathbf{R} \geq 0.79)$, moderate relative emitter discharge class ( $\mathbf{R}$ between 0.79 and 0.61) and low relative emitter discharge class $(\mathrm{R}<0.61)$.

For all $\boldsymbol{G W}$ treatments and treatments of WF and FF with $\boldsymbol{T S E}$, the values of $\mathbf{R}$ are higher than 0.79 for all times of operation. So, the values of $\mathbf{R}$ of these treatments for all operational times are in the range of the high class. For MF treatment with $\boldsymbol{T S E}$, the values of $\mathbf{R}$ are higher than 0.79 for operational times less than $900 \mathrm{~h}$. By increasing the times of operation than $900 \mathrm{~h}$, the $\mathbf{R}$ values decreased than 0.79 to reach 0.72 at 1440 h. For NF treatment with $\boldsymbol{T S E}$, the values of $\mathbf{R}$ are higher than 0.79 for operational times less than $540 \mathrm{~h}$, by increasing the operational times than $540 \mathrm{~h}$, the $\mathbf{R}$ values decreased to reach 0.62 and 0.56 at $1080 \mathrm{~h}$ and $1440 \mathrm{~h}$, respectively.

From Fig. (2) we can concluded that the values of relative emitter discharge (R) were decreased for all treatments by increasing the operational times. By decreasing the $\mathbf{R}$ values, the emitters clogging degree were increased, (Capra and Scicolone, 2004). WF and FF treatments increased the values of $\mathbf{R}$ compared to $\mathbf{N F}$ and $\mathbf{M F}$ for both water qualities. At the end of the experiment, the minimum value of $\mathbf{R}$ was 0.56 for treatment of NF using TSE. While the maximum values of $\mathbf{R}$ were 0.95 and 0.918 for treatments WF with $\boldsymbol{G W}$ and WF with $\boldsymbol{T S E}$, respectively. 


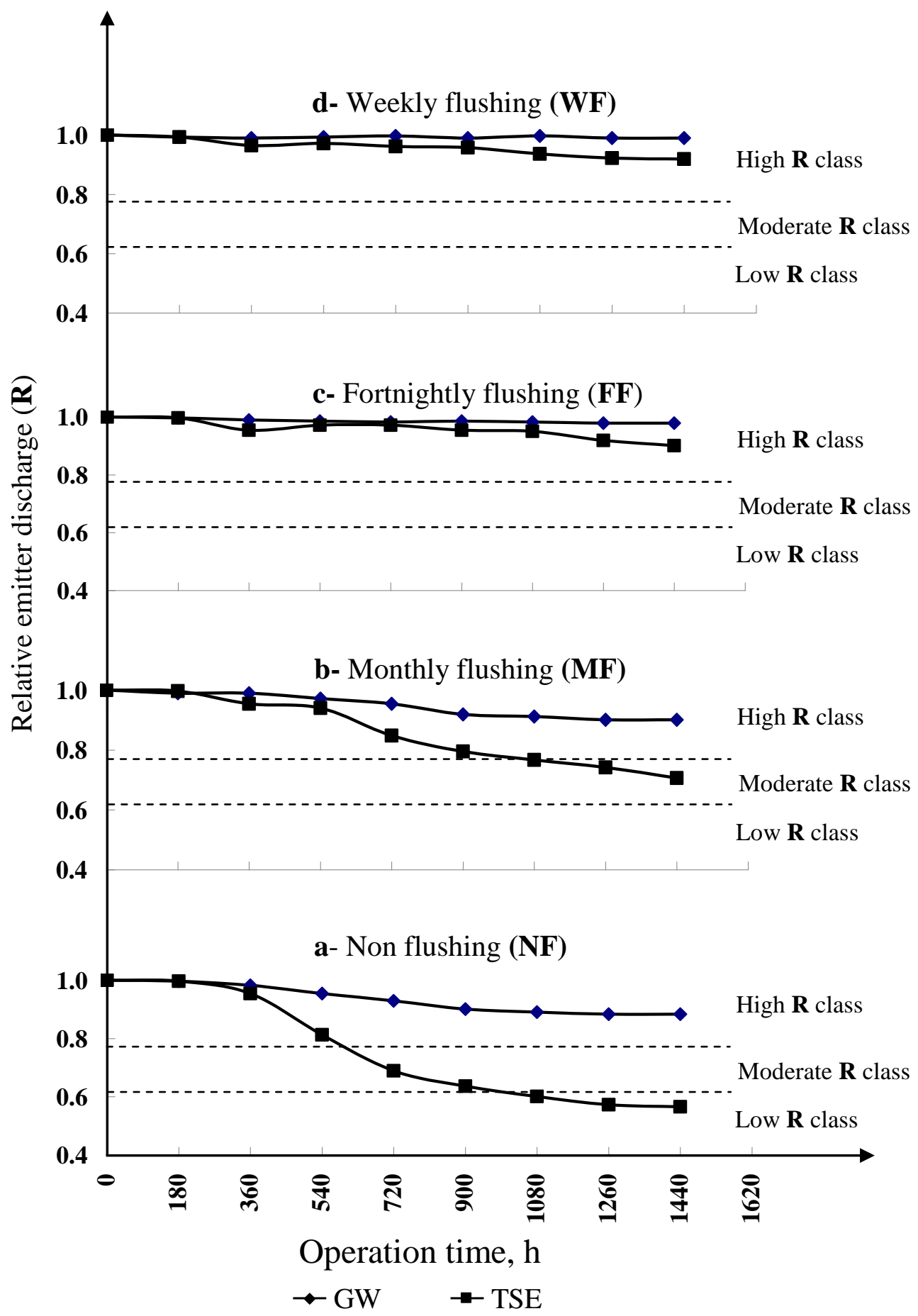

Fig. (2): Effect of water quality and laterals flushing frequency on relative emitter discharge (R) during the experiment 


\section{Coefficient of variation of emitter discharge (CV) during the experiment}

The coefficient of variation of emitter discharge (CV) for four laterals flushing frequency treatments for the application of both $\boldsymbol{G W}$ and $\boldsymbol{T S E}$ during the experiment are shown in Fig. 3. It is clear that the values of CV vary with water quality, laterals flushing frequency and operational time. The value of $\mathbf{C V}$ is greatly influenced by $\boldsymbol{T S E}$ in comparison with $\boldsymbol{G W}$. The values of $\mathbf{C V}$ for $\mathbf{N F}$ treatment increased greatly with the operational time in comparison with that of $\mathbf{F F}$ and $\mathbf{W F}$ treatments.

For $\mathbf{W F}$ and $\mathbf{F F}$ treatments, there are no significant differences $(\mathrm{P}>0.05)$ for the values of $\mathbf{C V}$ between the $\boldsymbol{G W}$ treatment and the $\boldsymbol{T S E}$ treatment. Also, there are no significant differences $(\mathrm{P}>0.05)$ for the values of $\mathbf{C V}$ between the FF and WF treatments. For MF treatment, the difference in values of $\mathbf{C V}$ between the $\boldsymbol{G W}$ treatment and the $\boldsymbol{T S E}$ treatment is not significant $(\mathrm{P}>0.05)$ before $540 \mathrm{~h}$ of operational time, while after that time the values of $\mathbf{C V}$ for the $\boldsymbol{T S E}$ treatment increased greatly than those of $\boldsymbol{G W}$ treatment and achieved its maximum value 0.43 at the end of operational time. For NF treatment, the difference in values of $\mathbf{C V}$ between the $\boldsymbol{G W}$ treatment and the $\boldsymbol{T S E}$ treatment is not significant (P > 0.05) before $360 \mathrm{~h}$ of operational time, while after that time the values of $\mathbf{C V}$ for the $\boldsymbol{T S E}$ treatment increased greatly than those of ground water treatment and achieved its maximum value 0.70 at the end of operational time. There are significant differences $(\mathrm{P}>0.05)$ for the values of $\mathbf{C V}$ between the NF, MF and FF treatments with $\boldsymbol{G W}$.

At the end of the experiment, for the $\boldsymbol{G W}$ treatment, the $\mathbf{C V}$ values for treatments WF and FF are relatively small 0.04 and 0.09, respectively. While, the $\mathbf{C V}$ values for $\mathbf{N F}$ and $\mathbf{M F}$ treatments are moderate 0.25 and 0.16, respectively. For the $\boldsymbol{T S E}$ treatment, the CV values of emitter discharge for WF and FF treatments were 0.10 and 0.12, respectively. While, the $\mathbf{C V}$ values for treatments $\mathbf{N F}$ and $\mathbf{M F}$ were 0.70 and 0.43 respectively. $\boldsymbol{T S E}$ is turbid and rich in ions, organic materials and microorganisms (Ma et al., 2006). Consequently, the emitter is prone to partial or complete clogging with $\boldsymbol{T S E}$ which increased the $\mathbf{C V}$ values (Capra and Scicolone, 2007). 
According to the criteria proposed by Bralts and Kesner (1983), WF treatment with both the $\boldsymbol{G W}$ and $\boldsymbol{T S E}$ and FF with the $\boldsymbol{G W}$ are in a well performance situation for their $\mathbf{C V}$ values less than 0.11, FF treatment with $\boldsymbol{T S} \boldsymbol{E}$ and $\mathbf{M F}$ and $\mathbf{N F}$ treatments with $\boldsymbol{G W}$ are in a moderate performance situation for their $\mathbf{C V}$ values in the range of $0.11-0.29$, whereas NF and MF treatments with $\boldsymbol{T S E}$ are in a poor performance situation for their $\mathbf{C V}$ values larger than 0.29. From the above mentioned, it is clear that WF treatment with both the $\boldsymbol{G W}$ and $\boldsymbol{T S E}$ had a smaller values of $\mathbf{C V}$, Then WF treatment is recommended for the $\boldsymbol{G W}$ and $\boldsymbol{T S E}$ to keep high emitters performance for long operational time.

\section{Distribution uniformity (DU) and Cristiansen uniformity coefficient $(\mathrm{CU})$ values during the experiment}

The calculated values of $\mathbf{D U}$ and $\mathbf{C U}$ for four laterals flushing frequency treatments for the application of both $\boldsymbol{G W}$ and $\boldsymbol{T S E}$ during the experiment are shown in Fig. (4). Similar to the $\mathbf{C V}$, the $\mathbf{D U}$ and $\mathbf{C U}$ values varies with water quality, laterals flushing frequency and operational time. The values of DU and $\mathbf{C U}$ are greatly influenced by $\boldsymbol{T S E}$ in comparison with $\boldsymbol{G W}$. The values of $\mathbf{D U}$ and $\mathbf{C U}$ for $\mathbf{N F}$ treatment decreased greatly with the operational time in comparison with those of $\mathbf{F F}$ and $\mathbf{W F}$ treatments.

For $\mathbf{W F}$ and $\mathbf{F F}$ treatments for the $\boldsymbol{G W}$ had the highest values of DU and CU greater than $96 \%$ in the entire experimental period. With the TSE, the DU and CU of WF and FF treatments decrease with the increase of operational time as its value larger than $1080 \mathrm{~h}$, and are $91.15 \%$ and $89.02 \%$ respectively at the end of the experiment. For MF treatment, the difference in values of $\mathbf{D U}$ and $\mathbf{C U}$ between the $\boldsymbol{G} \boldsymbol{W}$ treatment and the $\boldsymbol{T S E}$ treatment is not significant $(\mathrm{P}>0.05)$ before $540 \mathrm{~h}$ of operational time. After $540 \mathrm{~h}$ of operational time, both the DU and $\mathbf{C U}$ values decrease greatly for $\boldsymbol{T S E}$. At the end of the experiment, the DU and $\mathbf{C U}$ of MF treatment are 58.9 and $56.1 \%$ respectively, for the $\boldsymbol{T S E}$ treatment, and $89.0 \%$ and $86.8 \%$, respectively for the $\boldsymbol{G W}$ treatment. For NF treatment, the difference in values of $\mathbf{D U}$ and $\mathbf{C U}$ between the $\boldsymbol{G W}$ treatment and the $\boldsymbol{T S E}$ treatment is not significant $(\mathrm{P}>0.05)$ before $360 \mathrm{~h}$ of operational time. 


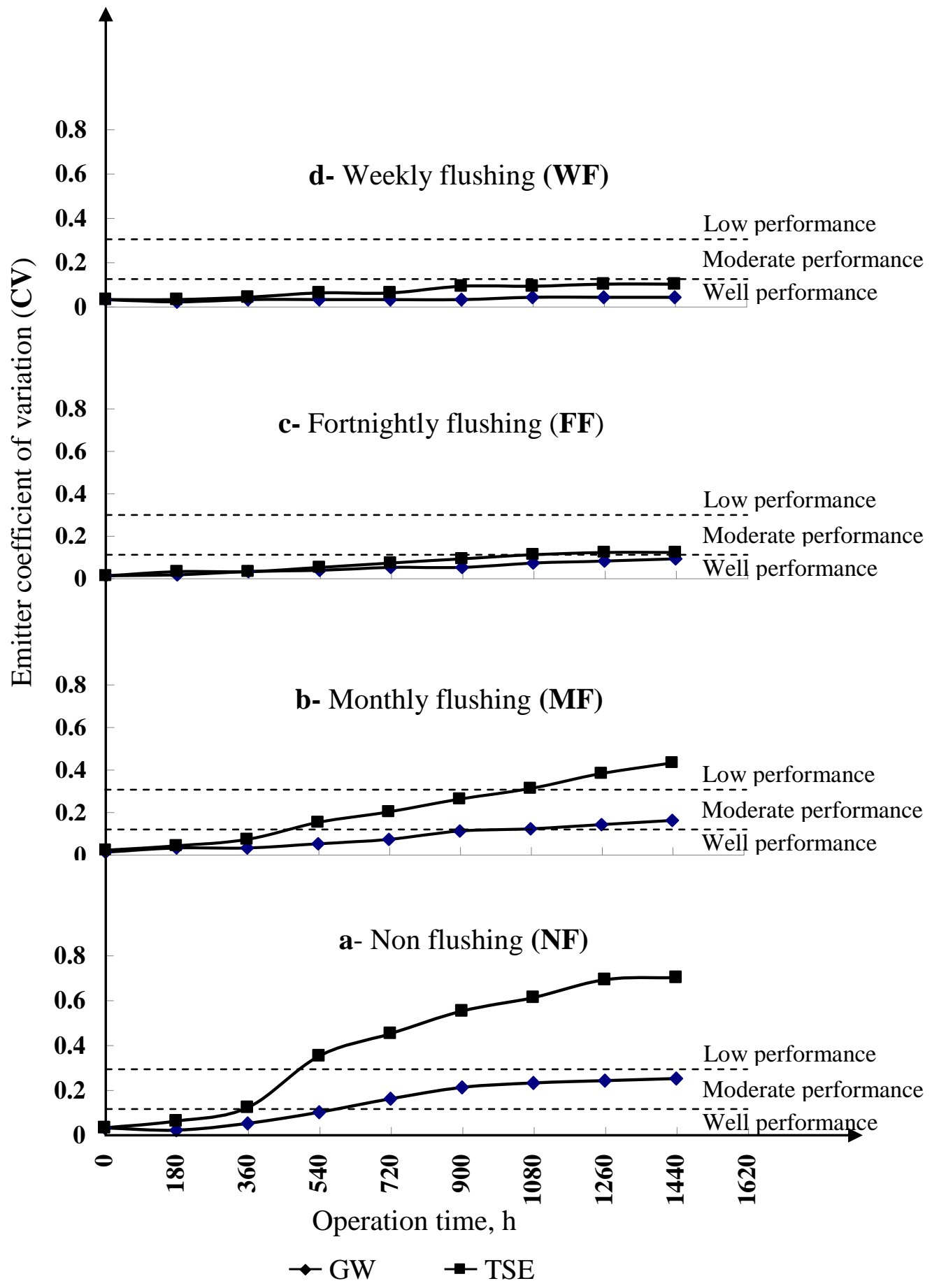

Fig. (3): Effect of water quality and laterals flushing frequency on coefficient of variation $(\mathbf{C V})$ during the experiment 


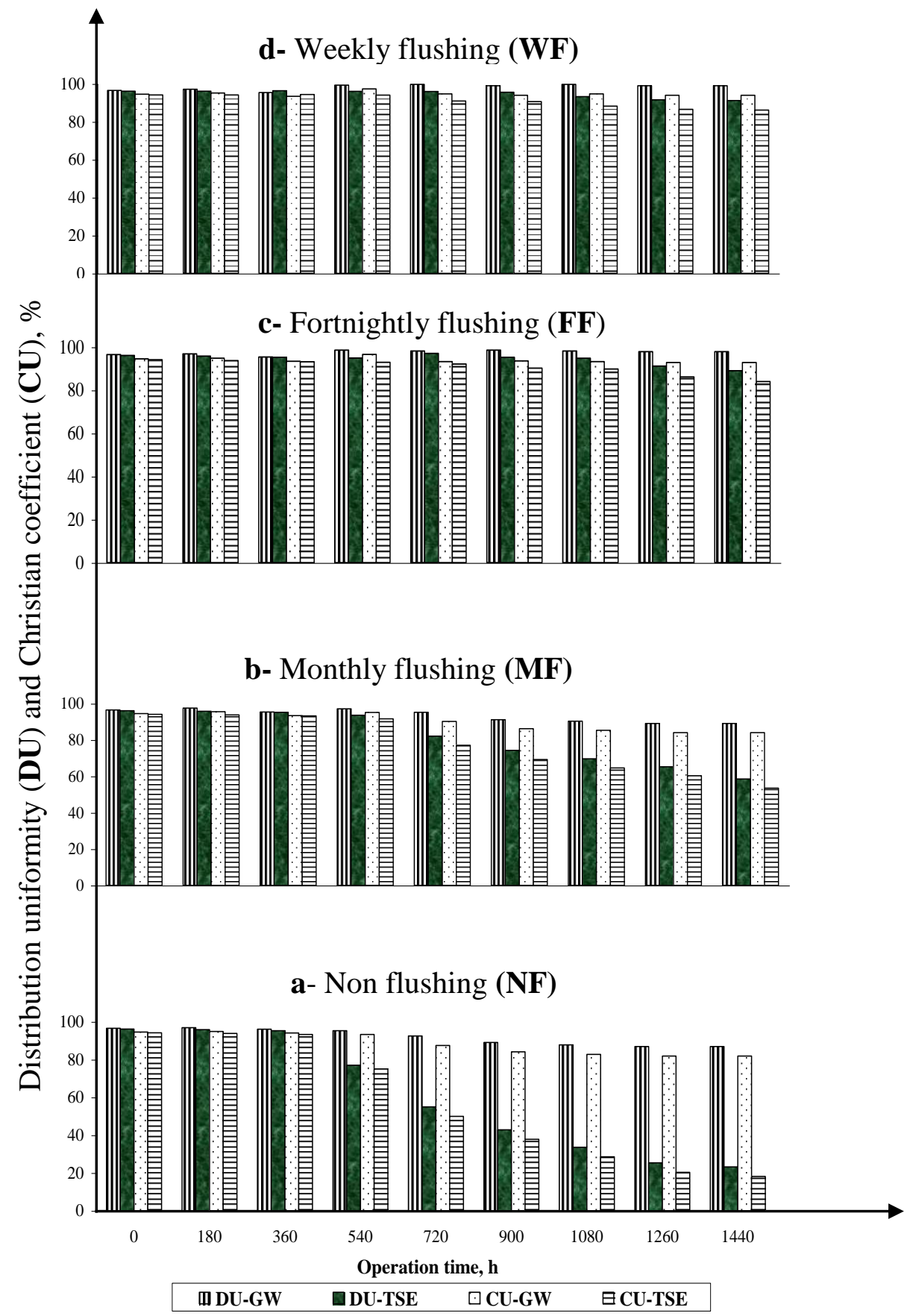

Fig. (4): Effect of water quality and laterals flushing frequency on distribution uniformity (DU) and Christian coefficient (CU) during the experiment. 
After $360 \mathrm{~h}$ of operational time, both the DU and CU values decrease greatly for the $\boldsymbol{T S E}$ treatment,. At the end of the experiment, the DU and CU of NF treatment are 23.12 and $19.35 \%$, respectively for the $\boldsymbol{T S E}$ treatment, and $86.8 \%$ and $85.2 \%$, respectively for the $\boldsymbol{G W}$. From the above mentioned, it is clear that WF treatment with both the $\boldsymbol{G W}$ and TSE had a higher values of DU and CU for total operational time.

\section{CONCLUSION}

From this investigation, the following conclusion can be made:

1. The factors of water quality, laterals flushing frequency and operational time had high significant effect on the values of $\mathbf{q}_{\mathbf{r}}, \mathbf{C v}, \mathbf{R}$, DU and CU.

2. The minimum values of $\mathbf{q}_{\mathbf{r}}$ were $1.06 \%$ and $8.12 \%$ for treatment $\mathbf{W F}$ using $\boldsymbol{G W}$ and $\boldsymbol{T S E}$, respectively. While the maximum value of $\mathrm{q}_{\mathbf{r}}$ was 43.3\% for treatment of NF using $\boldsymbol{T S E}$.

3. The maximum values of $\mathbf{R}$ were 0.95 and 0.918 for treatment $\mathbf{W F}$ using $\boldsymbol{G W}$ and $\boldsymbol{T S} \boldsymbol{E}$, respectively. While the minimum value of $\mathbf{R}$ was 0.56 for treatment of NF using $\mathbf{T S E}$.

4. The minimum values of $\mathbf{C V}$ were 0.04 and 0.10 for treatment $\mathbf{W F}$ using $\boldsymbol{G W}$ and $\boldsymbol{T S E}$, respectively. While the maximum value of CVwas 0.70 for treatment of NF using TSE.

5. The maximum values of $\mathbf{D U}$ and $\mathbf{C U}$ were $98.8 \%$ and $93.9 \%$, respectively for treatment WF using $\boldsymbol{G W}$. While the minimum values of DU and CU were $23.1 \%$ and $19.0 \%$, respectively for treatment of NF using $T S E$.

In a conclusion, WF treatment showed a suitable emitters performance than another treatments of laterals flushing. So, WF treatment is recommended for the $\mathbf{G W}$ and TSE to keep high emitters performance for long operational time.

\section{REFERENCES}

Ahmed, B. O.; T. Yamamoto; H. Fujiyama and K. Miyamoto. 2007. Assessment of emitter discharge in microirrigation system as affected by polluted water. Irrig. Drain Syst. 21, 97-107.

ASAE Standards. 2003. EP405.1: Design and installation of microirrigation system. St. Joseph, Michigan, ASAE. 
Ayars, J. E.; D. A. Bucks; F. R. Lamm and F. S. Nakayama. 2007. Microirrigation for Crop Production. Design, Operation, and Management. $1^{\text {st }}$ edition. Elsevier, Radarweg 29, PO Box 211, 1000 AE Amsterdam, The Netherlands, pp. 1-26

Bralts, F.V. and D. C. Kesner. 1983. Drip irrigation field uniformity estimation. Trans. ASAE 26, 1369-1374.

Capra, A. and B. Scicolone. 2004. Emitter and filter test for wastewater reuse by drip irrigation, Agric. Water Manage. 68 (2), 135-149.

Capra, A. and B. Scicolone. 2007. Recycling of poor quality urban wastewater by drip irrigation systems. J. Cleaner Prod. 15, 1529-1534.

De Kreij, C.; A. M. M. van der Burg and W. T. Runia. 2003. Drip irrigation emitter logging in Dutch greenhouses as affected by methane and organic acids. Agric. Water Manage. 60, 73-85.

Guo, X. Y.; Z. Dong and H. L. Gong. 2006. Influence of reclaimed water irrigation on microbial community on lawn soil. Chin. Environ. Sci. 26 (4), 482-485

Hills, D. J. and M. J. Brenes. 2001. Microirrigation of wastewater effluent using drip tape. Appl. Eng. Agric. 17 (3): 303-308.

Hills, D. J.; M. A. Tajrishy and G. Tchobanoglous. 2000. The influence of filtration on ltraviolet disinfection of secondary effluent for microirrigation, Trans. ASAE 43 (6), 1499-1505.

Lamm, F. R. and R. C. Camp. 2007. Microirrigation for Crop Production. Design, Operation, and Management. $1^{\text {st }}$ edition. Elsevier, Radarweg 29, PO Box 211, 1000 AE Amsterdam, The Netherlands, pp. 473-551.

Liu, H. and G. Huang. 2009. Laboratory experiment on drip emitter clogging with fresh water and treated sewage effluent. Agric. Water Manage. 96 (5), 745-756.

Keller, J. and D. Karmeli. 1974. Trickle irrigation design parameters. Trans. ASAE 17 (4), 678-684.

Ma, M.; Z. Huang; Z. Miao and L. Hou. 2006. Reclaimed water's influence on corn growth under different irrigation mode. J. Irrig. Drain. 25 (4), 68-70.

Nakayama, F. S. and D. A. Bucks. 1991. Water quality in drip/trickle irrigation: a review. Irrig. Sci. 12, 187-192. 
Nakayama, F. S.; B. J. Boman and D. J. Pitts. 2007. Microirrigation for Crop Production. Design, Operation, and Management. $1^{\text {st }}$ edition. Elsevier, Radarweg 29, PO Box 211, 1000 AE Amsterdam, The Netherlands, pp. 389-430.

Peng, Z.; P. Yang; S. Ren and Y. Wang. 2006. Impact characteristics of reclaimed water irrigation on the growth rate, chlorophyll and carotenoids contents of lawn grasses. Trans. CSAE 22 (10), 105-108.

Puig-Bargues, J.; G. Arbat; J. Barragan and F. Ramırez de Cartagena. 2005. Hydraulic performance of drip irrigation subunits using WWTP effluents. Agric. Water Manage. 77, 249-262.

Ravina, I.; E. Paz; Z. Sofer; A. Marcu; A. Shisha; G. Sagi; Z. Yechialy and Y. Lev. 1997. Control of clogging in drip irrigation with stored treated municipal sewage effluent, Agric. Water Manage. 33 (2-3), pp. 127-137.

Tajrishy, M. A.; D. J. Hills and G. Tchobanoglous. 1994. Pretreatment of secondary effluent for drip irrigation, J. Irrig. Drain. Eng. 120 (4), 716-731.

Yang, J.; G. Huang; Q. Huang; H. Liu; J. He and G. Meng. 2003. A preliminary study on turfgrasses water consumption and irrigation schedule with irrigation of sewage effluent. Acta Agrestia Sin. 11 (4), 329-333

Zeng, D. and W. Zhu. 2004. Discussion on problems of sewage irrigation and countermeasures in China. Agric. Res. Arid Areas 22 (4), 221-224.

Zhang, J.; W. Zhao; Z. Wei; Y. Tang and B. Lu. 2007. Numerical and experimental study on hydraulic performance of emitters with arc labyrinth channels. Comput. Electron. Agric. 56, 120-129.

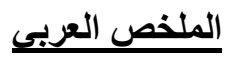

تأثير نوعية المياه وتكرار غسيل الخطوط الفرعية على أداء النقاطات

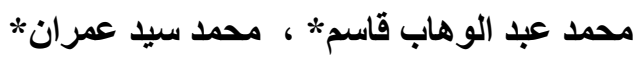

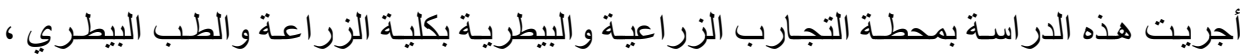

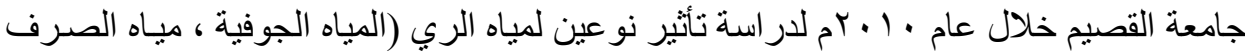

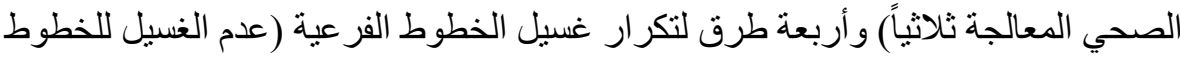

* أستاذ مساعد بقسم الهندسة الزراعيةـ كلية الزراعةـ جامعة القاهرة. 


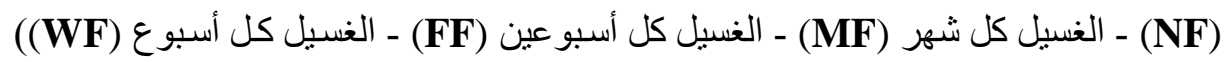

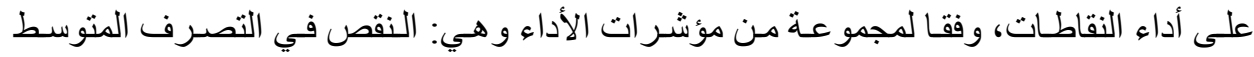

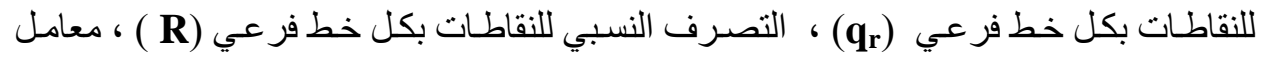

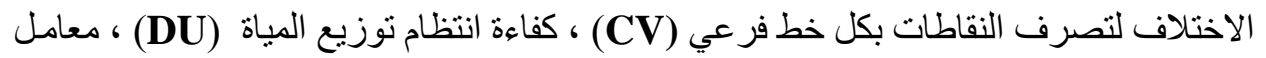

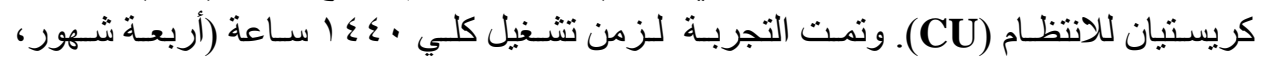

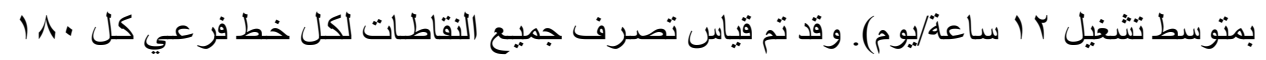
ساعة تشغيل .

\section{وقد أظهرت النتائج ما يلى:-}

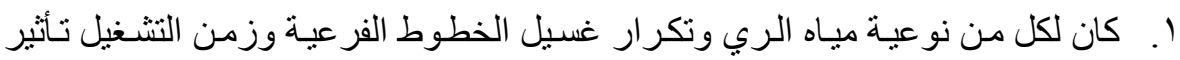

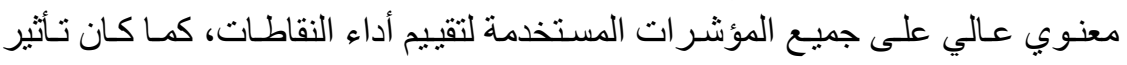
التفاعل بينهم عالي المعنوية على هذه المؤشرات.

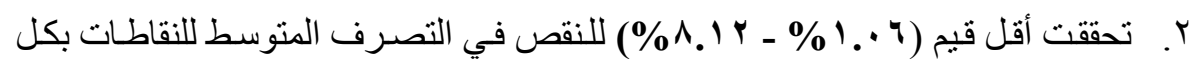

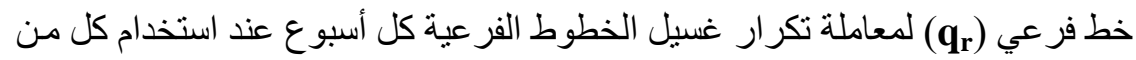

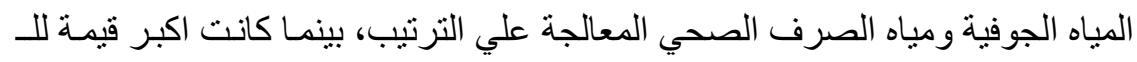

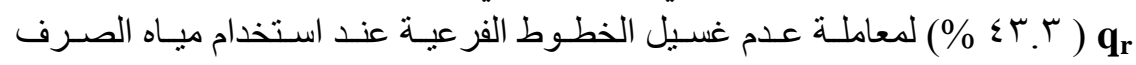
الصحي المعالجة.

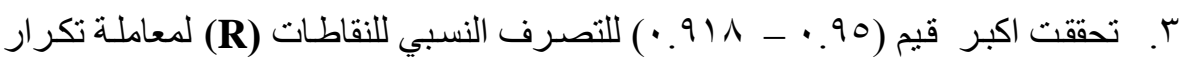

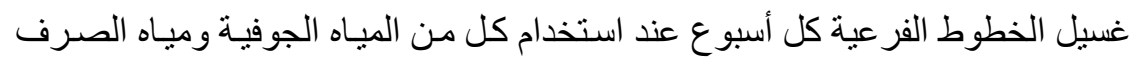

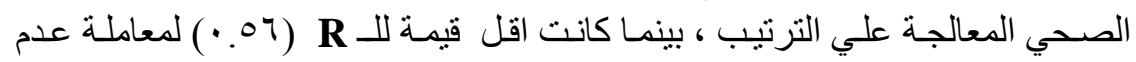
غسيل الخطوط الفر عية عند استخدام مياه الصرف الصني الصحي المعالجة.

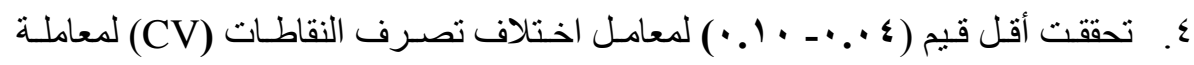

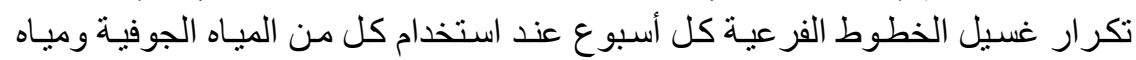

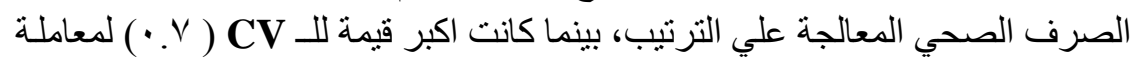
عدم غسيل الخطوط الفرعية عند استخدام مياه الصرف الصناب الصحي المعالجة.

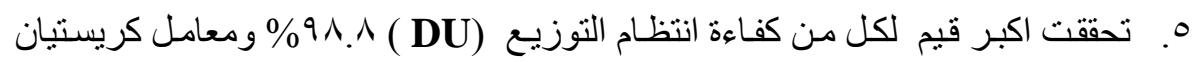

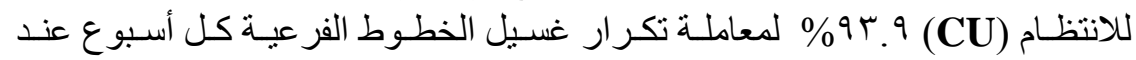

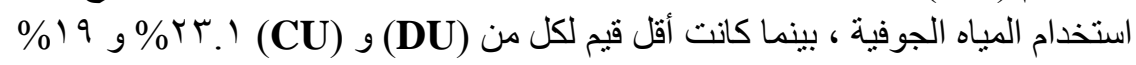
علي الترتيب لمعاملة عدم غسيل الخطوط الفر عية عند استخدام ميـاه الصرف الصنام الصحي

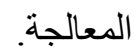

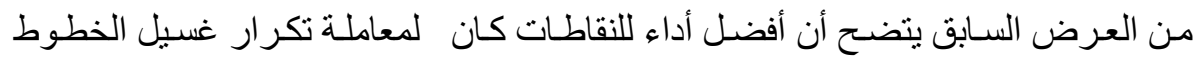

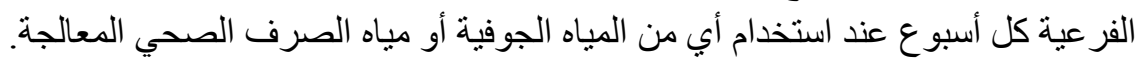

